\title{
Validity of genus Perostrongylus Schlegel, 1934 with new data on Perostrongylus falciformis (Schlegel, 1933) in European badgers, Meles meles (Linnaeus, 1758): distribution, life-cycle and pathology
}

Georgiana Deak', Andrei Daniel Mihalca ${ }^{1 *}$, Joerg Hirzmann², Vito Colella³, Flaviu Alexandru Tăbăran4, Maria Alfonsa Cavalera ${ }^{3}$, Florinel Gheorghe Brudașcă ${ }^{5}$, Christian Bauer ${ }^{2}$, Angela Monica lonică ${ }^{1}$, Amer Alićc , Domenico Otranto ${ }^{3}$ and Călin Mircea Gherman ${ }^{1}$

\begin{abstract}
Background: A century of debates on the taxonomy of members of the Metastrongyloidea Molin, 1861 led to many reclassifications. Considering the inconstant genus assignation and lack of genetic data, the main aim of this study was to support the validity of the genus Perostrongylus Schlegel, 1934, previously considered a synonym of Aelurostrongylus Cameron, 1927, based on new molecular phylogenetic data and to understand its evolutionary relationships with other metastrongyloid nematodes.
\end{abstract}

Results: Specimens of lungworm collected from European badgers in Germany, Romania and Bosnia and Herzegovina were morphologically and molecularly (rDNA, cox1) characterized. From a phylogenetic standpoint, Perostrongylus is grouped with high support together with the genera Filaroides van Beneden, 1858 and Parafilaroides Dougherty, 1946 and includes probably two species: Perostrongylus falciformis (Schlegel, 1933), a parasite of Meles meles in Europe and $P$. pridhami (Anderson, 1962), a parasite of Neovison vison in North America. Perostrongylus and Aelurostrongylus are assigned to different clades. Aelurostrongylus becomes a monotypic genus, with the only species Aelurostrongylus abstrusus (Railliet, 1898). In addition, we provide morphological and morphometric data for the first-stage (L1), secondstage (L2), and third-stage (L3) larvae of P. falciformis and describe their development in experimentally infected Cornu aspersum snails. The pathological and histopathological lesions in lungs of infected European badgers are also described. This is the first record of $P$. falciformis in Romania.

Conclusions: Molecular phylogenetic and morphological data support the validity of the genus Perostrongylus, most probably with two species, P. falciformis in European badgers and P. pridhami in minks in North America. The two genera clearly belong to two different clades: Perostrongylus is grouped together with the genera Filaroides and Parafilaroides (both in the family Filaroididae Schulz, 1951), whereas Aelurostrongylus belongs to a clade with no sister groups.

Keywords: Perostrongylus, Aelurostrongylus, Metastrongyloidea, European badgers, mustelids

\footnotetext{
*Correspondence: amihalca@usamvcluj.ro

'Department of Parasitology and Parasitic Diseases, University of Agricultural

Sciences and Veterinary Medicine Cluj-Napoca, Cluj-Napoca, Romania

Full list of author information is available at the end of the article
}

(c) The Author(s). 2018 Open Access This article is distributed under the terms of the Creative Commons Attribution 4.0 International License (http://creativecommons.org/licenses/by/4.0/), which permits unrestricted use, distribution, and reproduction in any medium, provided you give appropriate credit to the original author(s) and the source, provide a link to the Creative Commons license, and indicate if changes were made. The Creative Commons Public Domain Dedication waiver (http://creativecommons.org/publicdomain/zero/1.0/) applies to the data made available in this article, unless otherwise stated. 


\section{Background}

A century of debates on the taxonomy of members of the superfamily Metastrongyloidea Lane, 1917 led to many reclassifications of these nematodes within a variety of families, subfamilies, genera and species [1, 2]. The genus Aelurostrongylus Cameron, 1927 was erected to accommodate Aelurostrongylus abstrusus (Railliet, 1898) [3] which was originally described by Mueller in 1890 [4] as Strongylus pusillus and renamed to Strongylus abstrusus by Railliet [5], because S. pusillus was preoccupied [6]. Later, the genus Protostrongylus Kamensky, 1905 was erected [7] and Strongylus abstrusus transferred to this new genus (as Protostrongylus pusillus), containing two other species, i.e. Protostrongylus rufescens (Leuckart, 1865), the type-species, and Protostrongylus commutatus (Diesing, 1851) [as Protostrongylus terminalis (Passerini, 1884)]. Interestingly, Kamensky used the early specific name as originally named by Mueller in 1890.

The definition of Aelurostrongylus as a new genus [3] was based mainly on the absence of cuticular bursal supports and the absence of "supporting fingers" of the spicular sheaths. Cameron [3] included only the type-species $A$. abstrusus in the newly erected genus.

Perostrongylus falciformis (Schlegel, 1933) was described from European badgers, Meles meles in Germany as Strongylus falciformis Schlegel, 1933 [8] due to the sickle-shaped spicules and one year later, transferred to the genus Filaroides van Beneden, 1858 as Filaroides falciformis [9]. In the same year, Schlegel [10] erected a new genus, Perostrongylus Schlegel, 1934 in order to include this nematode. The main characteristics to support the new genus were the reduced, truncated copulatory bursa of the males, and the presence of larvated eggs in the uterus of the females [10]. A few years later, Wetzel [11] suggested that $P$. falciformis should be transferred to the genus Aelurostrongylus, considering the genus Perostrongylus as a synonym, based on the morphology of the bursa and gubernaculum in males. In two subsequent reviews on this group of nematodes [12, 13], the genus Perostrongylus is listed as a synonym of Aelurostrongylus, based on Wetzel's suggestions, without further comments. In his taxonomic review, Dougherty [12] listed four species in the genus Aelurostrongylus: Aelurostrongylus abstrusus (Railliet, 1898); Aelurostrongylus brauni (von Linstow, 1897); Aelurostrongylus. falciformis (Schlegel, 1933); and Aelurostrongylus fengi (Hsü, 1935). The latter has been initially described as the type-species of Pulmostrongylus Hsü, 1935 [14], but Dougherty [12] considered this genus as a synonym of Aelurostrongylus while Anderson [15] and Lesage [16] as a subgenus of Protostrongylus. However, Seneviratna [13] as well as the authors of later keys and reviews $[17,18]$ maintained the validity of Pulmostrongylus. The generic allocation of $A$. brauni was also questioned [19]. Asakawa et al. [20] redescribed this species and assigned it to the newly established genus Viverrostrongylus Asakawa, 1986.

A new species belonging to genus Aelurostrongylus, A. pridhami was described by Anderson [21] in Neovison vison from Canada. Previously, the species was erroneously identified as A. falciformis [22]. The same author [19] highlighted that some species of the genus Aelurostrongylus (A. abstrusus and $A$. fengi) are oviparous, while others ( $A$. falciformis and $A$. pridhami) are ovoviviparous. Moreover, A. falciformis and $A$. pridhami differ from $A$. abstrusus with regard to the morphology of the bursa and spicules. Based on these differences, Anderson [19] suggested that the genus Perostrongylus should be reinstated, but later placed it as a subgenus of Aelurostrongylus [15, 17]. Subsequent publications continued to use the genus name Aelurostrongylus (synonymy of the genus [23]; A. falciformis [24-29], A. pridhami [27, 30-33]), while others accepted and used Perostrongylus (P. pridhami [34-42], P. falciformis [37, 43]). It is evident, that most European studies maintained the validity of Aelurostrongylus while the American studies predominantly used Perostrongylus. However, based on the data from Anderson [19], the two species are congeneric, sharing the same features.

The life-cycles of both species of Perostrongylus have been described in detail. Wetzel [11] studied the development of $P$. falciformis in several snail and slug species, and described the L1-L3 larval stages, but illustrated only L1 and L3. He also established the prepatent period in experimentally infected European badgers. The development of $P$. pridhami was described in slugs as well as in various terrestrial and aquatic snails, with detailed description and illustrations for L1-L3 larval stages [21]. The development of $P$. pridhami in American minks has also been described in detail [21, 37]. Anderson [21] demonstrated the infectivity to minks of L3 of $P$. pridhami from paratenic hosts (rodents, birds, amphibians and fish).

Similarly to most metastrongyloid nematodes, $P$. falciformis has an indirect life-cycle. Females are ovoviviparous and deposit in the alveoli thin-shelled eggs with larvae which subsequently hatch. Larvae and mature adult parasites are found in the alveoli, alveolar ducts and terminal bronchioles. L1 are coughed-up, swallowed and shed through the faeces. Prepatency in experimental infections was shown to be 1819 days. Larvae enter different species of land snails and moult twice to infective L3. European badgers become infected by eating snails or paratenic hosts. The development of L3 to adults in European badgers is not known [11]. Symptoms of infected European badgers vary from less severe to death, depending on lungworm infection rate and secondary bacterial infections. The associated lung lesions and different stages of verminous pneumonia in European badgers with minor to massive lungworm infections were 
lobular bronchopneumonia, diffuse bronchitis and widespread emphysema $[8,10]$. In minor infections, European badgers in good nutritional status often completely recovered after coughing out the worms, leading to the regression of inflammatory process and encapsulation and calcification of degraded worms and eggs in the form of small, cheesy calcareous nodules in the subpleura and parenchyma of lung lobes. The lungworm invasion affected predominantly young animals $[8,10,11,19]$.

Considering the rather inconstant genus assignation and lack of molecular data, the main aim of this study was to provide information to support the validity of the genus Perostrongylus based on new molecular phylogenetic data and to understand its evolutionary relationships with other lungworms of carnivores. In addition, morphological details of the larval stages of $P$. falciformis, as well as a detailed pathological and histopathological description of the lesions in European badgers are provided.

\section{Methods}

\section{Sample collection}

Thirty-two adult European badgers were collected from different localities in Europe (Table 1) and carcasses were examined by necropsy by removing the entire respiratory tract. The trachea, bronchi, and the bronchioles were longitudinally dissected and carefully examined under a stereomicroscope for the presence of parasites. Nematodes found encapsulated in small nodules on the surface of the lungs were collected, washed in saline solution and preserved in formaldehyde for morphological identification. Midbody fragments of nematodes were stored in $70 \%$ ethanol for DNA extraction and molecular identification.

\section{Morphological analysis}

Eight males and three females collected from two European badgers in Romania (CJ005077 from Hărman, Brașov County and CJ005086, from Charlottenburg, Timiș County) were examined as temporary mounts in lactophenol. Five morphometric features in males (body length, body width, oesophagus length, length of spicules, length of gubernaculum) and six morphometric features in females (body length, body width, oesophagus length, distance between the vulva and the caudal end, distance between the anus and the caudal end, distance between

Table 1 The examined samples and number of European badgers infected with $P$. falciformis

\begin{tabular}{llll}
\hline Country & $\begin{array}{l}\text { No. of European } \\
\text { badgers examined }\end{array}$ & Positive & Prevalence (\%) \\
\hline Romania & 27 & 9 & 33.3 \\
Bosnia and Herzegovina & 1 & 1 & nd \\
Germany & 4 & 3 & 75 \\
\hline
\end{tabular}

Abbreviation: nd not determined the vulva and anus) were evaluated. Furthermore, $50 \mathrm{~L} 1$ larvae collected from the lungs of the same European badgers were also measured (length and maximum width). Measurements were taken using an Olympus BX61 microscope, DP72 digital camera and the Cell ${ }^{\wedge}$ imaging software (Olympus Corporation, Tokyo, Japan). One male was available for measurements in Germany. No adult specimens were available for measurement from the European badger collected in Bosnia and Herzegovina. Additionally, larvae collected from the experimentally infected snails were also examined.

\section{Experimental life-cycle of $P$. falciformis in Cornu aspersum} First-stage larvae of $P$. falciformis were recovered from the lungs of a naturally infected European badger (CJ005086), hunted in Charlottenburg, Timiș County, Romania $\left(45.975825^{\circ} \mathrm{N}, 21.518763^{\circ} \mathrm{E}\right)$ by the Baermann method [44]. The resulted solution was collected into two $50 \mathrm{ml}$ Falcon tubes, centrifuged at $600 \times g$ for $3 \mathrm{~min}$ and the sediment examined under light microscopy. Larvae obtained were morphologically and molecularly identified as $P$. falciformis (based on sequence identity with morphologically confirmed adults). Single infective doses of $200 \mathrm{~L} 1$ each were collected and used for the infection of snails. Cornu aspersum snails not exposed to any nematodes of vertebrates were purchased from a commercial provider from Puglia, Italy. The snails were kept in a plastic box, covered with a fine mesh, in a temperature-controlled room $\left(21 \pm 2{ }^{\circ} \mathrm{C}\right)$ and fed lettuce every second day. Water was provided ad libitum. Moreover, the boxes were humidified twice a day. To exclude the presence of any previous parasitic infections, a subset of 10 snails were artificially digested and microscopically examined, one day before the infection. The experimental infection took place in the Unit of Parasitology of the Department of Veterinary Medicine of the University of Bari, Italy. Cornu aspersum snails $(n=30)$ were deprived of food $24 \mathrm{~h}$ before the infection and then placed individually into infection chambers, composed of six circular cell culture wells (Corning; CellBIND; Sigma-Aldrich, St. Louis, Missouri, USA). Each well contained a potato slice $(0.3-0.4 \mathrm{~mm}$ thick, obtained with a circular puncher) with the infective dose on the surface. The infection chambers were covered with a wet gauze cloth and secured with rubber bands. The snails were maintained in the infection chamber for $24 \mathrm{~h}$ and then released in the rearing box.

Larval development of $P$. falciformis was assessed by artificial digestion [45] of five randomly selected snails at 3 (T1), 6 (T2), 10 (T3), 15 (T4), 20 (T5) and 30 (T6) days post-infection (dpi). At each dpi, the suspension obtained from the gastropod digestion was microscopically examined and, when present, larvae were isolated and preserved in $70 \%$ ethanol. Larvae were then cleared 
and examined as temporary mounts in glycerol and digital images and measurements were taken using Leica $\mathrm{LAS}^{\ominus}$ AF 4.1 software.

\section{Molecular analysis}

The specimens used for molecular analysis are shown in Table 2. DNA was isolated from one male, one female fragment and three pools of L1 collected separately from three infected European badgers in Germany, using the DNeasy Blood \& Tissue Kit (Qiagen, Hilden, Germany) according to the manufacturer's protocol. The ribosomal DNA (rDNA) region including partial $18 \mathrm{~S}$ rRNA gene, internal transcribed spacer 1 (ITS1), 5.8S rRNA gene, internal transcribed spacer 2 (ITS2) and partial $28 S$ rRNA gene and a partial sequence of the mitochondrial cytochrome $c$ oxidase subunit 1 gene ( $\operatorname{cox} 1)$ were all amplified using nematode-specific primers. For the rDNA region we used combinations of the forward primers N18SF1, NF1 and $\mathrm{NC} 1$ and the reverse primers $\mathrm{D} 3 \mathrm{~B}, \mathrm{NC} 2$ and $\mathrm{NC} 5 \mathrm{BR}$ [44-49]. For the cox 1 sequence we used the primers MetCOI-F1 and JB4.5 [50-52]. PCR was performed with HOT FIREPol ${ }^{\bullet}$ Blend Master Mix (Solis BioDyne, Tartu, Estonia), $200 \mathrm{nM}$ final concentration of forward and reverse primers each and $100 \mathrm{ng}$ of nematode DNA in a $50 \mu \mathrm{l}$ reaction volume. PCR cycling conditions were as follows: $15 \mathrm{~min}$ activation/initial denaturation at $95^{\circ} \mathrm{C}, 35$ cycles of $20 \mathrm{~s}$ denaturation at $95{ }^{\circ} \mathrm{C}, 30 \mathrm{~s}$ annealing at $54{ }^{\circ} \mathrm{C}$ and $2 \mathrm{~min}$ extension at $72{ }^{\circ} \mathrm{C}$, followed by a $5 \min 72{ }^{\circ} \mathrm{C}$ final elongation. Amplicons were analysed on 1.5\% agarose gels, gel-purified, cloned into pDrive vector (Qiagen, Hilden, Germany) and sequenced by an external service provider (LGC Genomics, Berlin, Germany). Sequence chromatograms were checked manually and complete sequences, assembled from overlapping amplicons, were submitted to the GenBank database under the accession numbers KY365435-KY365437.

Genomic DNA was extracted from two adult nematodes from Romania, using a commercial kit (Isolate II
Genomic DNA Kit, Bioline, UK), according to the manufacturer's instructions. For each nematode, PCR amplification of a $\sim 700 \mathrm{bp}$ fragment of the $\operatorname{cox} 1$ gene and of the internal transcribed spacer 2 (ITS2, $\sim 500 \mathrm{bp}$ ) of the rRNA gene were performed, using primers and protocols available in literature $[47,51]$. The amplicons were purified using a commercial kit (Isolate II PCR and Gel Kit, Bioline, UK) and sequenced using an external service (performed by Macrogen Europe, The Netherlands).

Genomic DNA from L1 collected from one European badger from Bosnia and Herzegovina was extracted using a commercial kit (DNeasy Blood \& Tissue Kit, Qiagen, GmbH, Hilden, Germany), in accordance with the manufacturer's instructions, and a partial fragment of the ribosomal internal transcribed spacer 2 (ITS2) was amplified as previously described [47]. Amplicons were purified and sequenced in both directions using the same primers as for PCR, employing the Taq Dye Deoxy Terminator Cycle Sequencing Kit (v.2, Applied Biosystems) in an automated sequencer (ABI-PRISM 377). Sequences were aligned using the Geneious R9 software package (http://www.geneious.com) and compared (BLASTn) with those available in the GenBank database (http:/ blast.ncbi.nlm.nih.gov/Blast.cgi).

Additionally, the DNA was isolated from three specimens of each larval stage collected from experimentally infected snails, following the same protocol used for nematodes from Bosnia and Herzegovina.

\section{Phylogenetic analysis}

For molecular phylogenetic analyses datasets of sequences obtained from BLAST searches of the NCBI nucleotide (nt/nr) database using complete and partial Perostrongylus sequences were trimmed to homologous ends and realigned using the multiple sequence alignment program MAFFT 7 [53] with the L-INS-i method for the 28S D2-D3 and cox1 sequence data sets and the structure-aided Q-INS-i method for the ITS2 sequence

Table 2 Samples used for molecular analysis

\begin{tabular}{|c|c|c|c|c|c|c|}
\hline Sample type & Sample code & Locality of origin & Country & Target gene & Primers & GenBank ID \\
\hline$\overline{\text { Adult nematode }(f)}$ & CJ005077 & Hărman & Romania & ITS2 & $\mathrm{NC1} / \mathrm{NC2}^{\mathrm{a}}$ & MG733142 \\
\hline Adult nematode $(f)$ & CJ005086 & Charlottenburg & Romania & & & \\
\hline Adult nematode ( $f$ ) & CJ005077 & Hărman & Romania & $\cos 1$ & $\mathrm{LCO} / \mathrm{HCO}^{\mathrm{b}}$ & MG736730 \\
\hline Adult nematode $(f)$ & CJ005086 & Charlottenburg & Romania & & & \\
\hline Adult nematode $(\mathrm{m})+\mathrm{L} 1$ pools & DE-FD-Mm3 & Fulda & Germany & rDNA & NC18SF1/D3B & KY365435 \\
\hline Adult nematode $(\mathrm{m})+\mathrm{L} 1$ pools & DE-FD-Mm3 & Fulda & Germany & $\operatorname{cox} 1$ & MetCOIf1/JB4.5 & KY365437 \\
\hline L1 & OP137/17 & Semizovac & $\begin{array}{l}\text { Bosnia and } \\
\text { Herzegovina }\end{array}$ & ITS2 & $\mathrm{NC1} / \mathrm{NC}^{\mathrm{a}}$ & MG910460 \\
\hline $\begin{array}{l}\text { L1-L3 from experimentally infected } \\
\text { Cornu aspersum }\end{array}$ & & & & ITS2 & $\mathrm{NC} 1 / \mathrm{NC2}^{\mathrm{a}}$ & MG733142 \\
\hline
\end{tabular}


data set. Phylogenetic trees were constructed using Bayesian analysis (MrBayes 3.2) (10,000 tree generations, sampling each 10, discarding first 250 trees) and TreeDyn for tree drawing at the phylogeny.fr platform [54]. The 285 D2-D3 data set included 25 taxa and sequences homologous to nucleotides (nt) 3053-3968 of the P. falciformis sequence (KY365435). The ITS2 data set included 26 taxa and sequences homologous to nt 25132983 (including $15 \mathrm{nt}$ of the flanking $5.8 S$ rRNA gene and $28 S$ rRNA gene). The cox 1 data set included 15 taxa and sequences homologous to nt 200-650 of KY365437.

\section{Histological analysis}

Pieces of lung tissues originating from two fresh (unfrozen) European badgers collected in Romania (CJ005077 from Hărman, Brașov County and CJ005086, from Charlottenburg, Timiș County) containing nodules with the nematodes were fixed in 10\% phosphate-buffered formalin for $24 \mathrm{~h}$, routinely processed, embedded in paraffin wax, cut into $4 \mu \mathrm{m}$ sections, and stained with haematoxylin and eosin (H\&E).

\section{Results}

Out of the 32 examined European badgers, P. falciformis was found in 13 animals from all countries (Table 1).

\section{Morphological description of the adults}

Adult worms show a pronounced sexual dimorphism, the females being larger than the males. Both sexes have a cylindrical body, uniformly coloured, elongated, thread-like, very thin and extremely coiled inside nodules, making the removal of intact specimens difficult. The cuticle at the anterior end is smooth and the mouth opening is placed terminally. The buccal cavity is small, rudimentary, and opened into a clavate oesophagus which is composed of a cylindrical part in the anterior two-thirds of its length and a posterior bulbous region (Fig. 1).

The posterior end of females is slightly curved with the vulvar and anal openings on the lower curvature (Fig. 2). Morphometric data are shown in Table 3. In the uterus, larvated eggs are clearly visible (Fig. 3), demonstrating the ovoviviparity (Fig. 4).

The morphometric data for the males are shown in Table 3. At the posterior end, the males have a small copulatory bursa, two dissimilar and highly curved spicules, and a well-developed gubernaculum (Fig. 5). The copulatory bursa (Fig. 5a, b) is undeveloped, bilobed, with two symmetrical, transparent, and indistinguishable lateral lobes. The lobes are supported by rays with different appearance and origins: ventral, lateral, externo-dorsal and median. The ventral ray is short and distally split into two branches, the ventro-ventral and ventro-lateral, both similar in size. The lateral ray is divided into three short branches

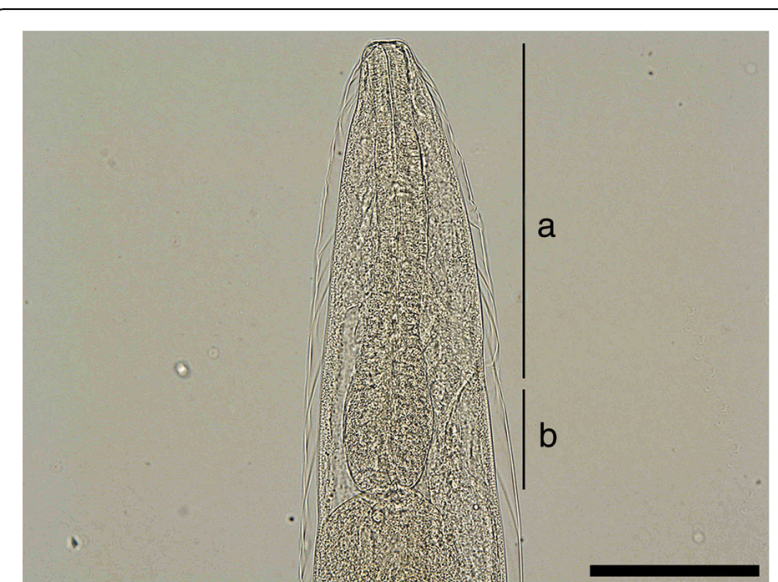

Fig. 1 Anterior end of Perostrongylus falciformis. a Cylindrical part of the oesophagus. $\mathbf{b}$ Bulbous region of the oesophagus. Scale-bar: $100 \mu \mathrm{m}$

with lobate appearance: externo-lateral and medio-lateral having a common trunk, slightly separated from the postero-lateral branch. The externo-dorsal ray is undivided, small and lobated. The median-dorsal ray is short, thick, and has two lateral micro-lobes and a median, sharp and short expansion (Fig. 5a). The spicules are chitinous, brown, slightly dissimilar, sickle-shaped, short, but stout. The anterior end of each spicule is knob-shaped or hemispherical and is followed by a bent caudal half, sharpened on an edge and thickened on the opposite side (Fig. 6a, b). The gubernaculum is placed between the spicules, being attached to them through protractor and retractor muscles. It is triangular, with prolonged and tapered anterior half, while the posterior end is bifurcated with a bi-lobed shape at the base (Fig. 6c).

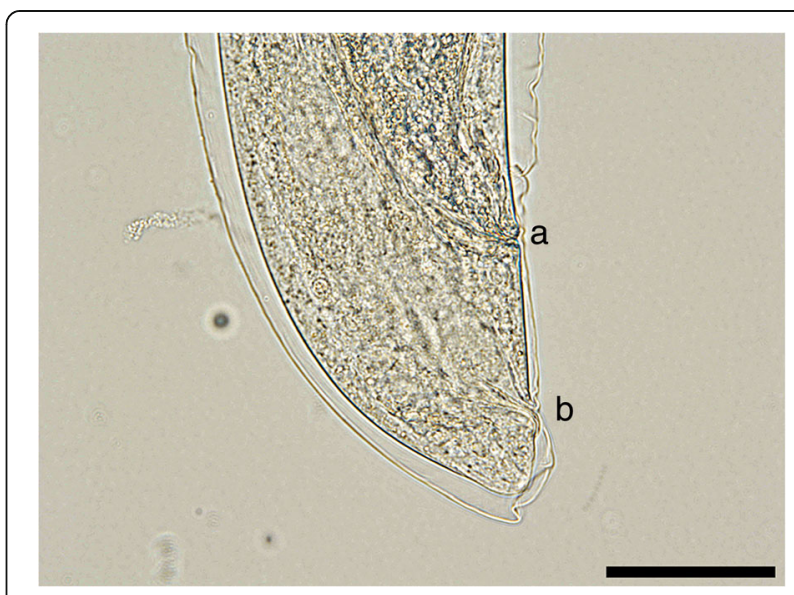

Fig. 2 Posterior end of female P. falciformis. a Vulva. b Anus. Scalebar: $50 \mu \mathrm{m}$ 
Table 3 Comparative morphometric data for Perostrongylus falciformis obtained in the present study. Measurements are in micrometres unless indicated otherwise

\begin{tabular}{|c|c|c|}
\hline Country & Romania & Germany $^{\mathrm{a}}$ \\
\hline Male & $(n=8)$ & $(n=1)$ \\
\hline Body length (mm) & $11.9-23.7$ & 26.0 \\
\hline Body width & $136-328$ & 160 \\
\hline Cuticle thickness at mid-body & $4-5$ & nd \\
\hline Distance excretory pore to cephalic end & $106-136$ & nd \\
\hline Distance anus to caudal end & $38-60$ & 40 \\
\hline Oesophagus length (total) & 207-395 & 209 \\
\hline Oesophagus length (cylindrical part) & $137-145$ & 131 \\
\hline \multicolumn{3}{|l|}{ Spicules length } \\
\hline Shorter spicule & $97-132$ & $117^{\mathrm{b}}$ \\
\hline Longer spicule & $103-150$ & \\
\hline Spicules maximum width & $17-23$ & 18 \\
\hline Gubernaculum length & $39-54$ & 48 \\
\hline Female & $(n=3)$ & \\
\hline Body length (mm) & $23-26$ & - \\
\hline Body width & $135-314$ & - \\
\hline Cuticle thickness at mid-body & $6-7$ & - \\
\hline Distance excretory pore to cephalic end & $132-222$ & - \\
\hline Oesophagus length & $267-273$ & - \\
\hline Distance vulva to anus & $94-105$ & - \\
\hline Distance vulva to caudal end & $176-184$ & - \\
\hline Distance anus to caudal end & $77-83$ & - \\
\hline Larva & $(n=50)$ & - \\
\hline Body length & $310-408$ & - \\
\hline Body maximum width & $14-28$ & - \\
\hline
\end{tabular}

Abbreviation: $n d$ not determined

${ }^{\mathrm{a}}$ No females and larvae were measured from Germany

${ }^{\mathrm{b}}$ The specimen was photographed from lateral view and only one spicule was visible

\section{Development of $P$. falciformis in Cornu aspersum}

Larval stages of $P$. falciformis were found in 27 out of 30 (90\%) experimentally infected snails. Numbers and developmental stages of larvae detected from experimentally infected snails are shown in Table 4. All control $C$. aspersum specimens digested prior to the infection $(n=$ 10) were negative for helminths.

A total of 293 larvae were found at the gastropod digestions. First-stage larvae were found from T1 until the end of the study period, whereas the first L3 was detected as soon as $10 \mathrm{dpi}$ and increasingly found until the end of the observational period (Table 4).

\section{Morphology of the larval stages of $P$. falciformis}

All measurements below are given in micrometres (Table 5). Metrical data are given as the range, with the mean in parentheses.

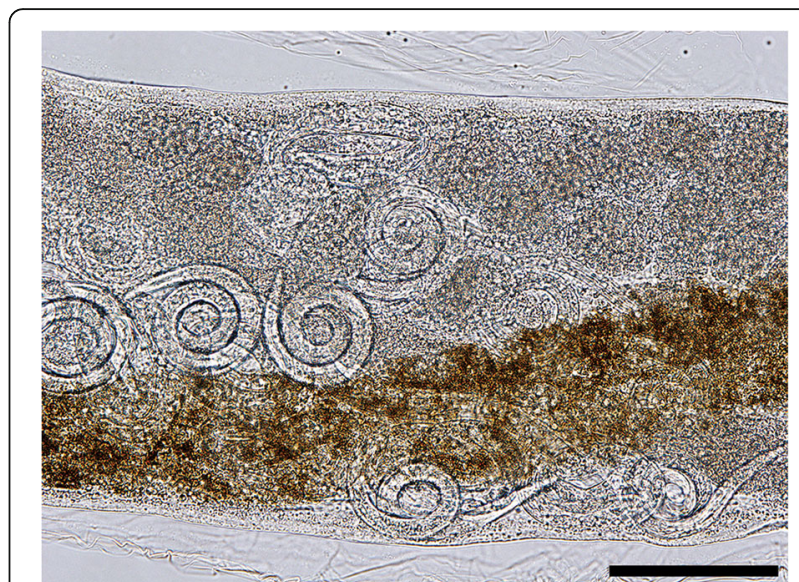

Fig. 3 Larvated eggs are clearly visible inside the uterus. Scale-bar: $100 \mu \mathrm{m}$

First-stage larvae collected from European badgers (Fig. 7a) measured 247-352 (317 \pm 41$)$ in length and 13-18 (14 \pm 1$)$ in width. The anterior extremity was featured by a narrowed, blunt end with a terminal buccal opening. The posterior extremity was 23-37 (32 \pm 5$)$ in length and characterized by a dorsal subterminal spine with a deep notch and a ventral bulge followed by an elongated sigmoid ending (Fig. 7a1).

Second-stage larvae (Fig. 7b) measured 403-443 (421 $\pm 13)$ in length and $30-33(31 \pm 1)$ in width. L2 were $\mathrm{C}$-shaped and filled with granules. The button-like anterior extremity as well the tail (Fig. 7b1) resembled that of L1. The anterior and posterior extremities displayed an empty-like appearance due to the presence of the cuticle of the L2 and the sheet of the previous larval stage.

Third-stage larvae (Fig. 7c) had a ventrally curved body measuring 459-496 (484 \pm 12$)$ in length and 23$33(27 \pm 3)$ in width. Some L3 were still encased in the

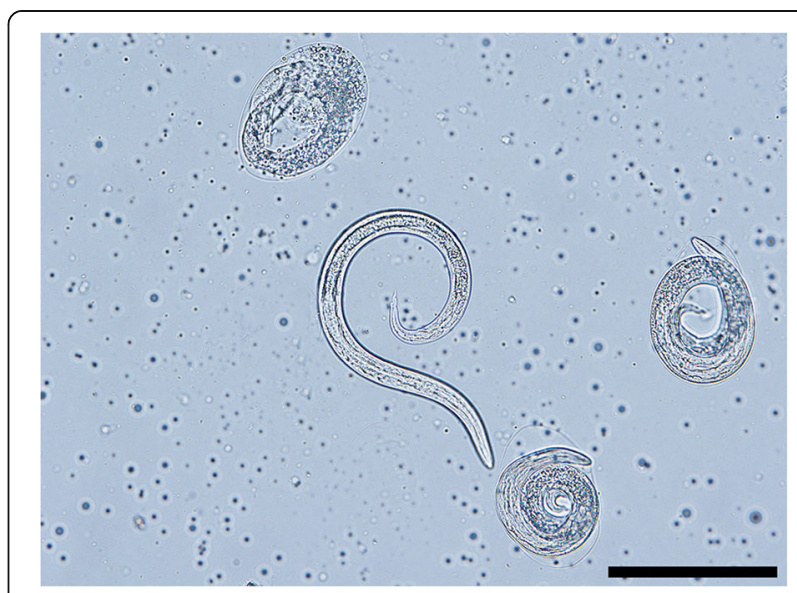

Fig. 4 Free L1 larva (center) and eggs with larvae of P. falciformis. Scale-bar: $100 \mu \mathrm{m}$ 

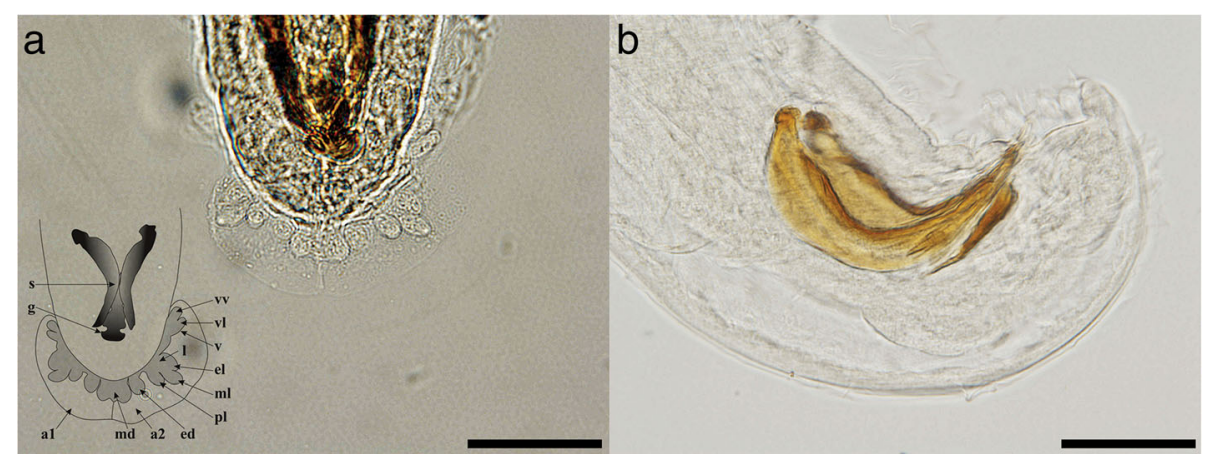

Fig. 5 Light microscopy and schematic representation of the posterior end of the males of Perostrongy/us falciformis. a Copulatory bursa, dorsal view (inset: schematic representation: a1, a2, lateral lobes; $v$, ventral ray; vv, ventro-ventral branch of ventral ray; vl, ventro-lateral branch of ventral ray; l, lateral ray; el, externo-lateral part of lateral ray; $\mathrm{ml}$, medio-lateral part of lateral ray; pl, posterio-lateral branch of lateral ray; ed, externo-dorsal ray; md, median-dorsal ray; s, spicules; g, gubernaculum) b Copulatory bursa, lateral view. Scale-bars: $50 \mu \mathrm{m}$

sheets of the previous stages. The anterior end was blunt, with a distinct buccal cavity followed by two stylet-like structures (Fig. 7c1). The muscular upper part of the oesophagus was cylindrical and followed by the glandular part which gradually enlarged in the bulbar oesophago-intestinal junction. The nerve-ring and the slightly posterior excretory pore were detected at 66-76 (72 \pm 3$)$ and 76-92 $(84 \pm 6)$ from the anterior extremity, respectively. The posterior extremity was 30-43 (39 \pm 4$)$ in length with a digitiform tip (Fig. 7c2).

\section{Molecular data and phylogenetic position of $P$. falciformis} For molecular analysis of $P$. falciformis a region of 4021 bp of the ribosomal DNA including the near complete 18S, ITS1, 5.8S, ITS2 and partial $28 S$ and a partial region of $1075 \mathrm{bp}$ of the mitochondrial cytochrome $c$ oxidase subunit 1 gene ( $\operatorname{cox} 1)$ were sequenced from the German isolates. Furthermore, in order to compare geographical

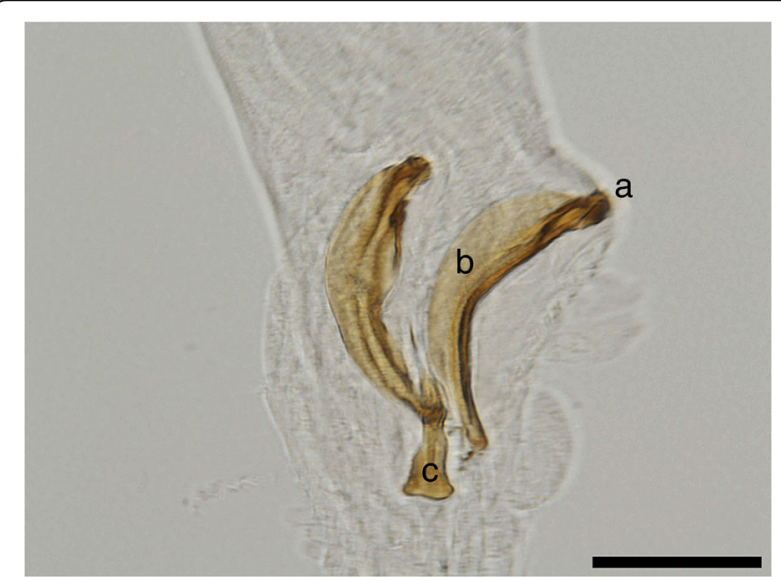

Fig. 6 Spicules and gubernaculum of $P$. falciformis. a Knob-shaped anterior end of the spicule. $\mathbf{b}$ The bent caudal half of the spicule. $\mathbf{c}$ Gubernaculum. Scale-bar: $50 \mu \mathrm{m}$ variants, the ITS2 region for $P$. falciformis isolates from Bosnia and Herzegovina and the ITS2 region and a partial cox 1 gene for isolates from Romania were sequenced. The cox 1 sequence from Romania was $99 \%$ identical to the German isolate, leading to three residue changes in the deduced amino acid sequence. The obtained ITS2 sequences of $P$. falciformis from the three countries were $100 \%$ identical, except one clone, suggesting an overall low geographical variation. The one exceptional rDNA clone (GenBank: KY365436) of the amplicon NF1-NC2 was from a female fragment from Germany, which had 15 SNPs (1802/1817 bp identities) compared to sequences from six other clones. This could be an additional haplotype or a rare intraspecific sequence variation in the rDNA repeats.

GenBank database searches with the P. falciformis $18 S$ and 285 rDNA sequences did not support the close phylogenetic relationship to A. abstrusus as would have been expected from the current taxonomic classification where Perostrongylus is considered as a subgenus of Aelurostrongylus [17]. Among the best matches for $P$. falciformis, according to alignment scores were species of the genera Parafilaroides and Filaroides. In contrast, the alignment score for A. abstrusus was lower and in the same range than to other metastrongyloid genera (not shown).

To further investigate the relationships among Perostrongylus and other metastrongyloid nematodes and to determine the molecular phylogenetic relation, analyses were performed with ITS2, partial $28 S$ (domains D2-D3) (Fig. 8) and partial cox1 sequences (Fig. 9) as biomarkers. These sequences were chosen due to their higher resolution at the species level and their length was adjusted to include a maximum of high scoring metastrongyloid nematodes from BLAST search on GenBank.

In the phylogenetic trees, $P$. falciformis and A. abstrusus were clearly separated, assigned to different clades, 
Table 4 Total number (mean no. per snail \pm SD) for the developmental stages of Perostrongylus falciformis larvae collected from five experimentally infected snails at 3 (T1), 6 (T2), 10 (T3), 15 (T4), 20 (T5) and 30 (T6) days post-infection

\begin{tabular}{lllll}
\hline & First-stage larvae & Second-stage larvae & Third-stage larvae & Total \\
\hline T1 & $19(3.8 \pm 2.7)$ & - & - & $19(6.3 \pm 11.0)$ \\
T2 & $10(2.0 \pm 1.6)$ & - & - & $10(3.3 \pm 5.8)$ \\
T3 & $13(2.2 \pm 1.8)$ & $59(11.8 \pm 2.6)$ & $1(0.2 \pm 0.4)$ & $73(24.3 \pm 30.6)$ \\
T4 & $3(0.6 \pm 0.9)$ & $78(15.6 \pm 7.2)$ & $4(0.2 \pm 0.4)$ & $82(27.3 \pm 43.9)$ \\
T5 & $4(0.8 \pm 1.1)$ & $37(7.4 \pm 5.7)$ & $23(4.6 \pm 4.1)$ & $45(15.0 \pm 19.1)$ \\
T6 & $5(1.0 \pm 1.7)$ & $36(7.2 \pm 3.8)$ & $64(21.3 \pm 15.6)$ \\
\hline
\end{tabular}

which was supported by all three genetic markers. Interestingly and consistent with discussed morphological similarities and forms of reproduction, the phylogeny inferred from the two rDNA sequence analyses, grouped P. falciformis together with species of the genera Parafilaroides and Filaroides (both within the family Filaroididae Schulz, 1951). The phylogenetic relationships of the Metastrongyloidea rDNA sequences correspond to previous studies [2]. There was strong support for groups of congeneric species and for the exclusion of the family
Crenosomatidae from other metastrongyloid taxa. The relations obtained here for the partial cox 1 sequence seem less consistent, because some morphologically proven congeneric species grouped with unrelated families, e.g. A. abstrusus with the Crenosomatidae and $A$. costaricensis with the Metastrongylidae.

\section{Pathology caused by $P$. falciformis in European badgers}

Grossly, multifocal, slightly elevated, well defined, small brown-black nodules were randomly distributed in the

Table 5 Measurements (in micrometres) of first- (L1), second- (L2) and third-stage (L3) larvae ( $n=10$ each) of Perostrongylus falciformis

\begin{tabular}{|c|c|c|c|c|}
\hline Measurements & L1 & L2 & L3 & Reference \\
\hline \multirow[t]{3}{*}{ Body length } & $\begin{array}{l}247-352 \\
(317 \pm 41)\end{array}$ & $\begin{array}{l}403-443 \\
(421 \pm 13)\end{array}$ & $\begin{array}{l}459-496 \\
(484 \pm 12)\end{array}$ & Present study \\
\hline & $270-370$ & $350-420$ & $340-440$ & [11] \\
\hline & - & - & $380-440$ & [63] \\
\hline \multirow[t]{3}{*}{ Maximum body width } & $\begin{array}{l}13-18 \\
(14 \pm 1)\end{array}$ & $\begin{array}{l}30-33 \\
(31 \pm 1)\end{array}$ & $\begin{array}{l}23-33 \\
(27 \pm 3)\end{array}$ & Present study \\
\hline & $10-17$ & 26 & $30-32$ & [11] \\
\hline & - & - & $24-27$ & [63] \\
\hline \multirow[t]{2}{*}{ Tail length } & $\begin{array}{l}23-37 \\
(32 \pm 5)\end{array}$ & $\begin{array}{l}35-46 \\
(41 \pm 3)\end{array}$ & $\begin{array}{l}30-43 \\
(39 \pm 4)\end{array}$ & Present study \\
\hline & $33-40$ & - & $30-46$ & [11] \\
\hline \multirow[t]{2}{*}{ Oesophagus length } & $\begin{array}{l}99-163 \\
(132 \pm 25)\end{array}$ & $\begin{array}{l}145-161 \\
(153 \pm 5)\end{array}$ & $\begin{array}{l}162-196 \\
(173 \pm 10)\end{array}$ & Present study \\
\hline & $130-150$ & 161 & 130-183 & [11] \\
\hline Intestine length & $130-150$ & 204 & $176-260$ & [11] \\
\hline Genital primordium, distance from posterior extremity & $\begin{array}{l}66-117 \\
(88 \pm 17)\end{array}$ & - & $\begin{array}{l}109-166 \\
(141 \pm 15)\end{array}$ & Present study \\
\hline \multirow[t]{2}{*}{ Nerve ring, distance from anterior extremity } & - & - & $\begin{array}{l}66-76 \\
(72 \pm 3)\end{array}$ & Present study \\
\hline & $85-90$ & - & - & [11] \\
\hline \multirow[t]{2}{*}{ Excretory pore, distance from anterior extremity } & - & - & $\begin{array}{l}76-92 \\
(84 \pm 6)\end{array}$ & Present study \\
\hline & $90-100$ & - & $75-90$ & [11] \\
\hline Ratio oesophagus length to body length & $0.399-0.464$ & $0.359-0.362$ & $0.352-0.395$ & Present study \\
\hline $\begin{array}{l}\text { Ratio distance from posterior extremity to genital } \\
\text { primordium to body length }\end{array}$ & $0.267-0.331$ & - & $0.237-0.334$ & Present study \\
\hline Anus to posterior extremity & 30 & 40 & 30 & [11] \\
\hline
\end{tabular}




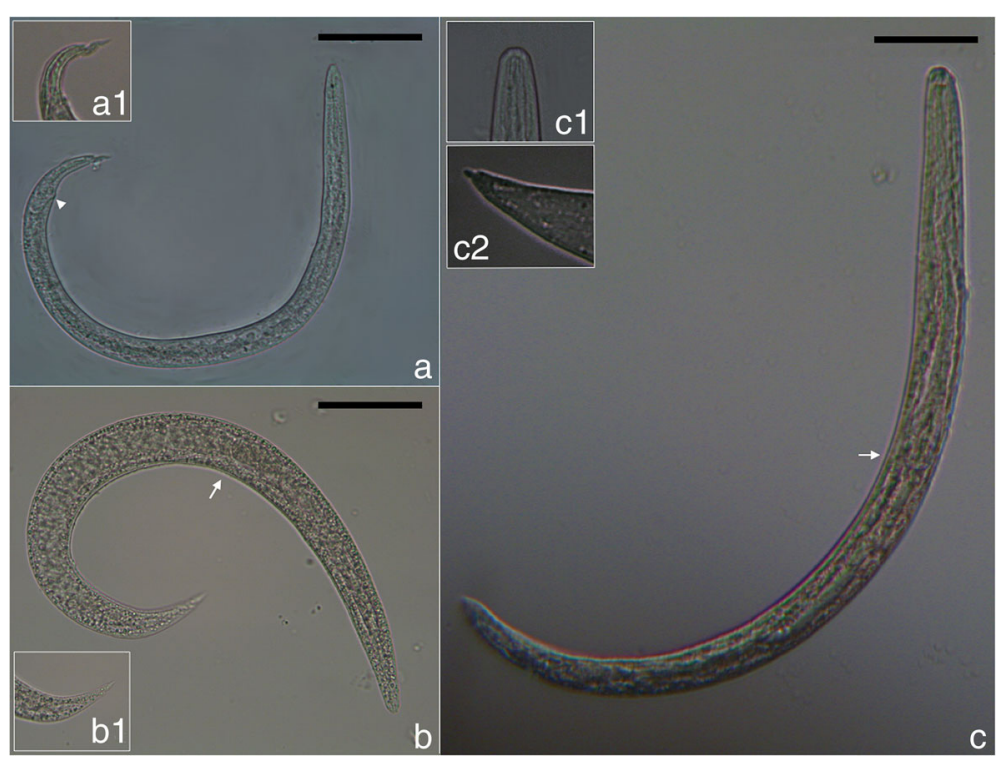

Fig. 7 Larval stages of P. falciformis. a First-stage larva and detail of the posterior extremity (a1) and well-visible anus (arrowhead). b Second-stage larva and detail of the posterior extremity (b1) and oesophago-intestinal junction (arrow). c Third-stage larva and details of the anterior (c1) and posterior (c2) extremities and oesophago-intestinal junction (arrow). Scale-bars: $50 \mu \mathrm{m}$

subpleural region of both lungs (Fig. 10a). Frequently, the parasite-containing nodules were associated with multifocal to coalescing areas of moderate alveolar emphysema (Fig. 10a). On the cut section, multiple, equally thin, blackish, partially coiled, $P$. falciformis adults were embedded in the lung parenchyma (Fig. 10b), without a significant preference for certain lung lobes. The bronchi were filled with a mucinous, foamy exudate (Fig. 10a).

Histologically, P. falciformis adults embedded in the lung parenchyma were present in high number in all examined histological sections. Few larval stages were also noted, especially in the bronchioles. Perostrongylus falciformis adults have a thin smooth cuticle, coelomyarianpolymyarian musculature and pseudocoelom with prominent intestine lined by cells that frequently contain brown-black granular pigment, and large uterus filled with developing eggs and larvae (Fig. 11c). Viable P. falciformis adults induce a mild inflammatory response consisting of macrophages (frequently laden with hemosiderin), occasional multinucleate giant cells, some lymphocytes and eosinophils (Fig. 11a-c). Few fibroblasts and thin collagen bundles were scattered between the above described cells. Smooth muscle hyperplasia of the terminal airways and alveolar emphysema were occasionally associated with the foci of interstitial pneumonia. Some viable adult nematodes are directly surrounded by a thin fibrous capsule. The inflammatory infiltrate extends from the parasite to the adjacent parenchyma, markedly expanding the alveolar walls. Alveolar emphysema was also focally associated with the foci of interstitial pneumonia. Bronchus-associated lymphoid tissue hyperplasia and alveoli filled by cellular infiltrate (as described above) and oedema were also observed.

Degenerated adult parasites (Fig. 11e) induced a marked inflammatory response consisting of poorly localized granulomas (sometimes centred on the parasite debris) and lympho-histiocytic and eosinophilic interstitial pneumonia. Occasionally, free $P$. falciformis larvae were present in the peribronchiolar and bronchiolar spaces (Fig. 11f). At these sites, the bronchiole walls were segmentally infiltrated by macrophages, epithelioid cells and multinucleate giant cells admixed with few eosinophils, fibroblasts and coiled larvae. Additionally, moderate to severe smooth muscle and bronchiolar epithelial hyperplasia with luminal obstruction by sloughed epithelial cells admixed with mucus, leukocytes (as described above) and parasite larvae were noted.

\section{Discussion}

This study provides the first molecular evidence for the validity of the genus Perostrongylus, which was previously synonymized with or considered a subgenus of Aelurostrongylus. With the exception of A. abstrusus, other species previously assigned to genus Aelurostrongylus, namely $A$. brauni and $A$. fengi were subsequently transferred to different genera. Due to the extremely poor description of $A$. brauni (a parasite originally described as Strongylus brauni from the Indian civet, Viverra zibetha), its classification as species inquirenda has already been suggested [19] and is now designated as Viverrostrongylus brauni [20]. Aelurostrongylus fengi was described from Crab-eating mongoose, Herpestes 


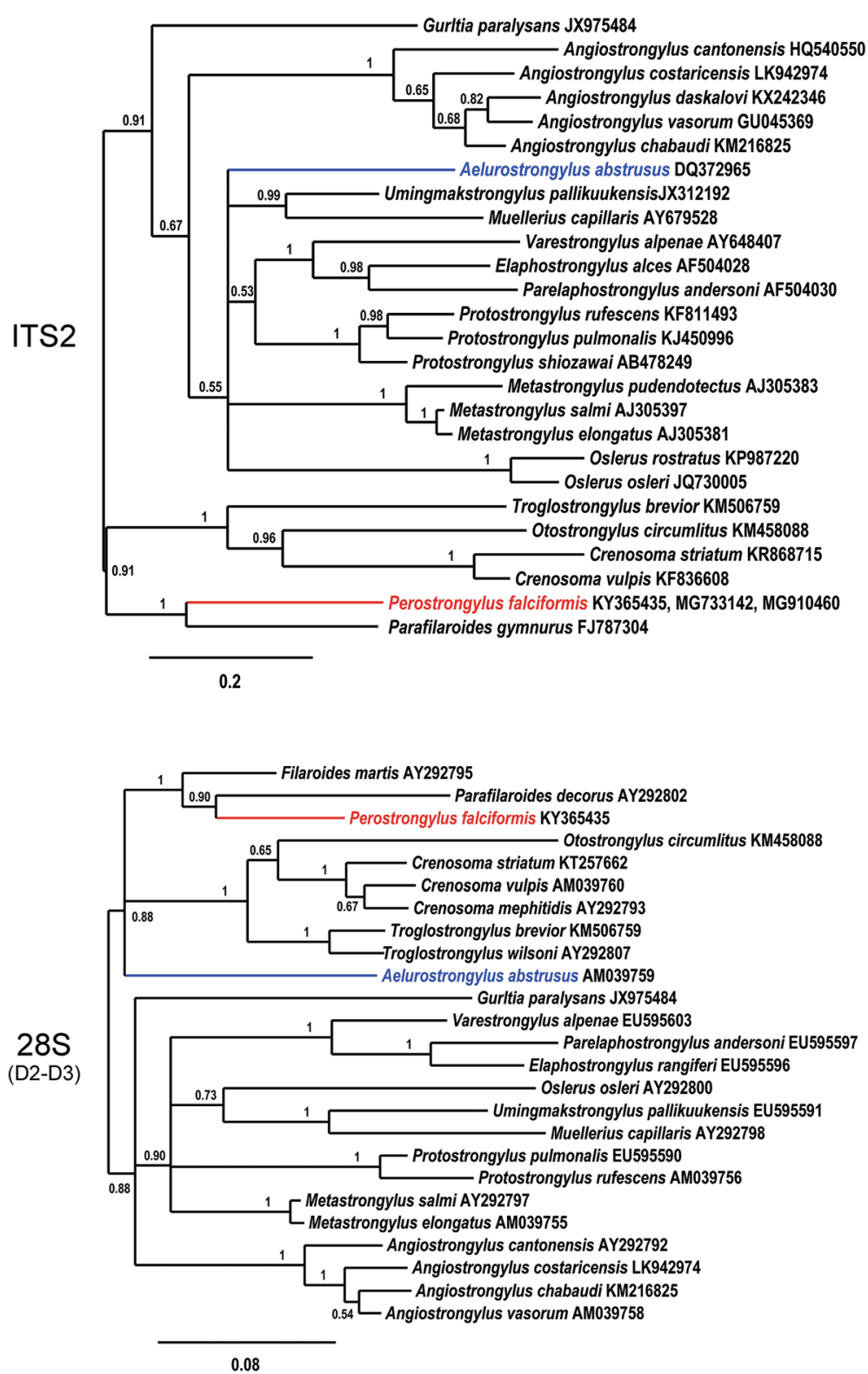

Fig. 8 Phylogenetic relationships of P. falciformis (red) with A. abstrusus (blue) and other metastrongyloid nematodes. Phylogenetic analysis based on ITS2 and partial 28S rDNA (domains D2-D3) sequences of metastrongyloid genera. Trees are constructed using Bayesian inference. Posterior probability values are shown next to the nodes; branches with values $<0.5$ are not shown. The scale-bar indicates the number of substitutions per site

urva, as Pulmostrongylus fengi. The taxonomic status of Pulmostrongylus (which includes already several species) is under debate, and currently it is considered a valid genus [18] or a subgenus of Protostrongylus [16]. Our molecular data provide evidence that $P$. falciformis and A. abstrusus are not congeneric. The conclusion drawn from this is the validity of the full genus status of Perostrongylus and the species name $P$. falciformis for the European badger lungworm.

Hence, the genus Aelurostrongylus becomes monotypic and includes only the type-species $A$. abstrusus.
Considering the rigorous rules of taxonomy, an interesting fact arises regarding A. abstrusus. As the first description of the species used the specific name pusillus [4], the valid name for this species should be Aelurostrongylus pusillus (see above). However, due its veterinary importance and worldwide use since more than a century under the name $A$. abstrusus, we suggest the latter name to be used.

From a phylogenetic standpoint, Perostrongylus is a valid genus and most probably includes two species: $P$. falciformis, a parasite of $M$. meles and possibly $M$. 


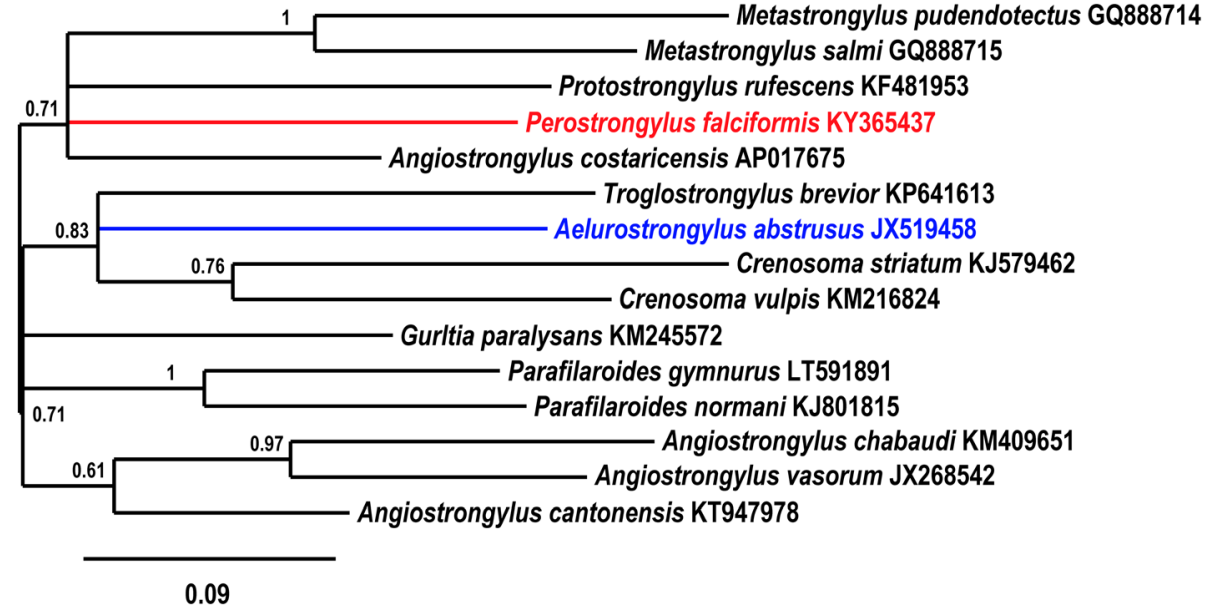

Fig. 9 Phylogenetic tree (Bayesian inference) using cox 1 sequences for P. falciformis (red), A. abstrusus (blue) and species of other metastrongyloid genera. Posterior probability values are shown next to the nodes; branches with values $<0.5$ are not shown. The scale-bar indicates the number of substitutions per site

erminea in Europe, and P. pridhami [21], a parasite of $N$. vison and Mustela erminea in North America. Our view is strongly supported by molecular phylogenetic data currently available only for P. falciformis. Further molecular studies are needed also for P. pridhami in North America, to conclude its phylogenetic position and relationships to $P$. falciformis.

Moreover, the phylogenetic analysis of the relationships of $P$. falciformis with species of other metastrongyloid genera clearly assigned Perostrongylus and Aelurostrongylus to different clades. Perostrongylus falciformis was grouped with high support together with the genera Filaroides and Parafilaroides (family Filaroididae), whereas $A$. abstrusus represented a single branch with no sister groups. Alignments of the internal transcribed spacer sequences (ITS1, ITS2) for different genera of the Metastrongyloidea are difficult because of the high variability in comparison to ribosomal RNA genes $(18 S, 28 S)$. We therefore performed the ITS2 multiple sequence alignment using a method of the program MAFFT which also considers secondary structures. However, the obtained correspondence between the analyses of ITS2 and the $28 S$ rDNA D2-D3 region corroborate the inferred phylogenetic position of $P$. falciformis

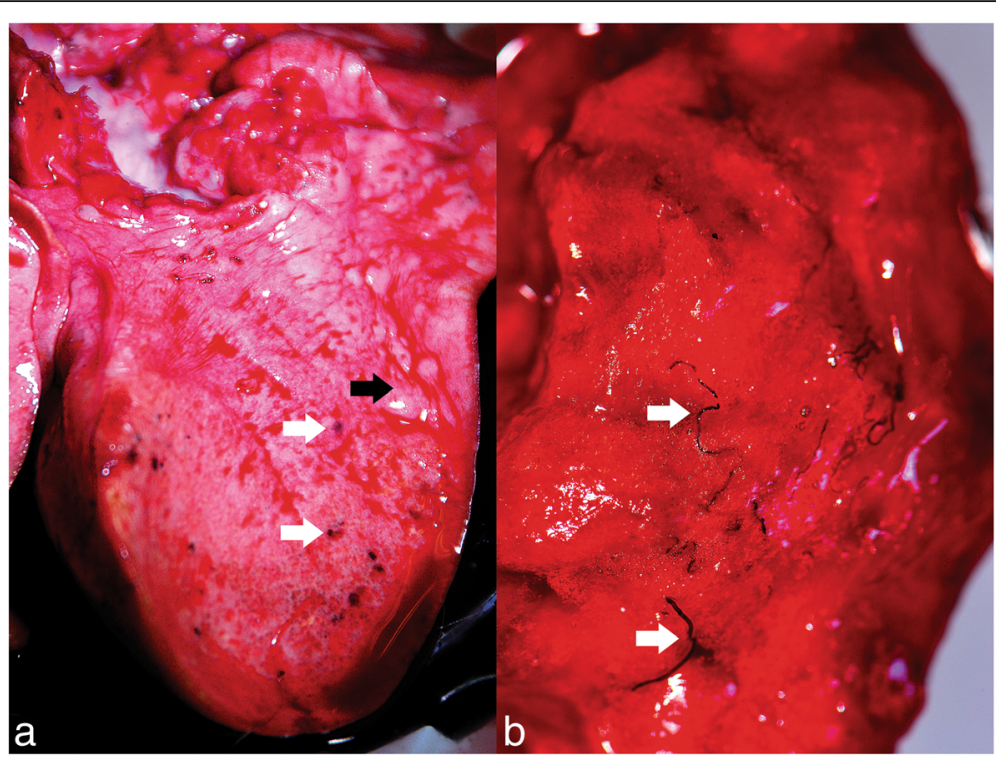

Fig. 10 Gross lesions produced by P. falciformis. a Adults in nodules in the subpleural space (white arrows) and the presence of alveolar emphysema (black arrow). b Adults in the pulmonary parenchyma (white arrows) 


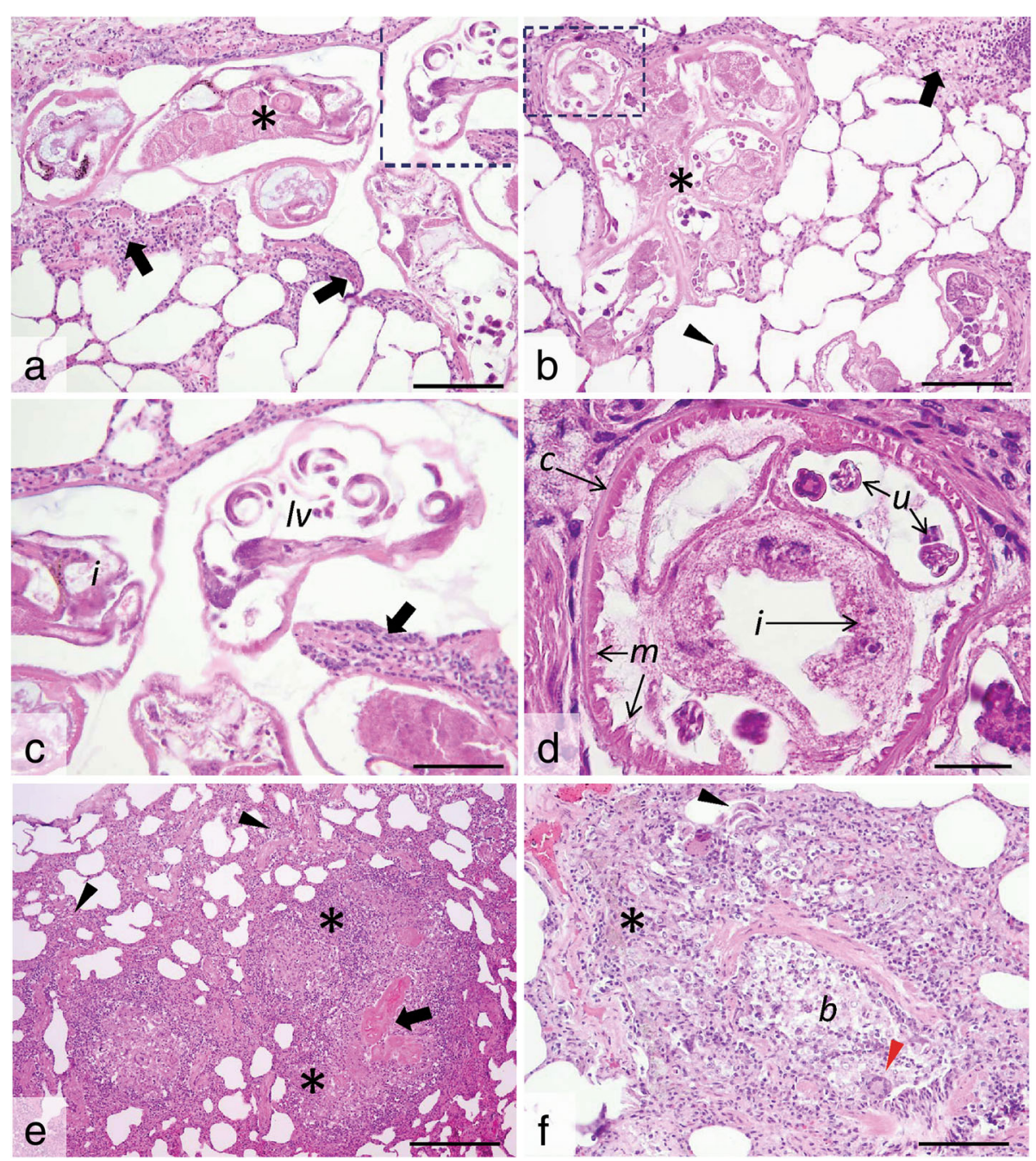

Fig. 11 Histological cross- and tangential sections of $P$. falciformis in the lung parenchyma. a, b. Viable $P$. falciformis adults (asterisks) coiled in the lung parenchyma and surrounded by a mild leukocyte reaction (many macrophages, occasional multinucleate giant cells, some lymphocytes and eosinophils) (black arrows) and smooth muscle hyperplasia. The alveolar walls are moderately expanded by the above described inflammatory cell population, with occasional alveolar wall rupture (arrowhead) and emphysema. c, $\mathbf{d}$ Detail of the marked areas in $\mathbf{a}$ and $\mathbf{b}$. The parasites have a thin smooth cuticle $(c)$ and pseudocoelom, coelomyarian-polymyarian musculature $(m)$, intestine $(i)$ with granular pigment and large uterus $(u)$ filled with developing larvae $(I V)$. The leukocyte reaction is also visible (black arrow in c). e, f. Free $P$. falciformis larvae (with thin walls and granular content) (black arrowhead in $\mathbf{f}$ ) are present in the bronchiolar (b) and peribronchiolar spaces, associated with prominent inflammatory reaction consisting of many macrophage (some laden with hemosiderin) (asterisk in $\mathbf{f}$ ), epithelioid cells and multinucleate giant cells (red arrowhead in $\mathbf{f}$ ) and few eosinophils and fibroblast. Degenerated parasites (black arrow in e) induce a marked inflammatory response consisting of ill-defined granulomas (asterisks in $\mathbf{e}$ ) and a locally-extensive interstitial lympho-histiocytic and eosinophilic pneumonia (arrowheads in e); H\&E staining, $\times 20$ $(\mathbf{a}, \mathbf{b}$ and $\mathbf{f}), \times 40(\mathbf{c}), \times 100$ (d) and $\times 10$ (e). Scale-bars: a, b, f, $100 \mu \mathrm{m} ; \mathbf{c}, 50 \mu \mathrm{m} ; \mathbf{d}, 25 \mu \mathrm{m} ; \mathbf{e}, 200 \mu \mathrm{m}$

close to the two genera of the Filaroididae within the superfamily Metastrongyloidea.

The close relationship of Perostrongylus, Filaroides and Parafilaroides in the molecular phylogeny is in good agreement with morphological characters and forms of reproduction. Males of species in all three genera have short, stout and arcuate spicules, a single-element gubernaculum and females are ovoviviparous. In contrast, males of $A$. abstrusus have slender (half the width of $P$. falciformis) and straight spicules, a gubernaculum of two joined equal elements and the females are oviparous [55]. The present paper also provides a very detailed morphological description of the adult stages of $P$. falciformis which was previously relatively brief $[8,10]$.

Both species of genus Perostrongylus are parasites of the Mustelidae. Perostrongylus falciformis has been reported so far only in European badgers from various countries in the western Palaearctic, including Germany [8, 11], Ukraine [56], Russia [57], Italy [58], UK [26], Norway [27], Poland [28], and Bosnia and Herzegovina 
[29]. Here we report for the first time the presence of $P$. falciformis in Romania. In a study from UK on stoats, unidentified nematodes were shown in a histological section of a lung [59]. Later, Simpson et al. [60], hypothesized, based on the morphology of the female in these histological sections that the nematodes could be $P$. falciformis. However, without morphological or genetic data, this remains only a presumption and we do not list stoats as confirmed hosts for $P$. falciformis.

Perostrongylus pridhami has been reported mainly in the American mink, N. vison in North America: Ontario, Canada [21, 22, 37, 42], Newfoundland, Canada [30], and Montana, USA [40] and in stoats, $M$. erminea from Newfoundland [30]. Torres et al. [32] mentioned P. pridhami in European badgers in Spain. However, this is highly unlikely, as it probably represents a misidentification of $P$. falciformis.

Interestingly, one study on invasive American minks in Spain [33] reported a specimen identified as Aelurostrongylus spp. As the specimen was not identified to the species level, it is not known if this represents $P$. pridhami, a natural parasite of this host in North America, but in an invasive population, or $P$. falciformis, which could suggest an adaptation from European badgers to invasive American minks.

Lungworms of genus Perostrongylus seem to occur with variable prevalence in mustelids across their distribution range (Table 6). Additionally to the overview in this table, unidentified lungworms were reported in $18 \%$ $(8 / 45)$ of European badgers in Germany, with pathological lesions consistent with those produced by $P$. falciformis [61]. In our opinion, a low prevalence or total absence of these parasites in studies with a reasonably large number of samples are likely the result of a rather superficial examination; probably $P$. falciformis is present in European badgers across their distribution range.

The data presented here indicate that $C$. aspersum is a suitable intermediate host of $P$. falciformis. However, in a series of laboratory infection studies, larval development from L1 to L3 was demonstrated to occur in two slug species [Deroceras agreste (Linnaeus, 1758) and Arion hortensis (Férussac, 1819)] and five species of terrestrial snails [Trochulus hispidus (Draparnaud, 1801), Cepaea hortensis (Müller, 1774), C. nemoralis (Linnaeus, 1758), Euomphalia strigella (Draparnaud, 1801) and Succinea putris (Linnaeus, 1758)] [11, 62].

After 24 hours, the L1 were found coiled between the muscle fibres of the snails' foot and the first moult occurred at 6-8 dpi at room temperature (or as long as 14 days at lower temperatures) [11, 62]. In the present study, the first L2 larvae were found at 10 dpi (however, the previous examination time was $6 \mathrm{dpi}$. Wetzel [11] mentions the second moult at 10-12 dpi. In our study, the first L3 were found at $10 \mathrm{dpi}$, but the largest numbers were present in snails at $30 \mathrm{dpi}$. Wetzel [11] also mentioned that these time frames are slightly variable according to the species of snail used, but no other details were provided. Wetzel [11, 62] described in detail L1-L3 larval stages and provided drawings for L1 and L3. These morphological details are largely consistent with our results (Table 5), with only minor differences. In addition, our present work provides the first detailed photomicrographs of L1-L3.

The life-cycle of $P$. pridhami described in North America [21] showed a role as potential intermediate hosts for several experimentally infected species of aquatic snails [Physa integra (Haldeman, 1841), Gyraulus deflexus (Sandberger, 1858), G. crista (Linnaeus, 1758), Ampullaria cuprina Reeve, 1856] as well as terrestrial snails [Zonitoides arboreus (Say, 1816), Discus cronkhitei (Newcomb, 1865), Novisuccinea ovalis (Say, 1817), Anguispira alternate (Say, 1816)] or slugs [Deroceras gracile (Müller, 1774)] [21]. As in P. falciformis [62], larvae of $P$. pridhami penetrate the foot of snails [21]. Stockdale [37] succeeded to infect terrestrial snails by

Table 6 Reported prevalence for Perostrongylus spp.

\begin{tabular}{|c|c|c|c|c|}
\hline Species & Host & Country & $\begin{array}{l}\text { Prevalence (\%) } \\
\text { (infected/examined) }\end{array}$ & Reference \\
\hline P. falciformis & Meles meles & Germany & $50.0(6 / 12)$ & {$[10]$} \\
\hline P. falciformis & Meles meles & Poland & $22.2(2 / 9)$ & [28] \\
\hline P. falciformis & Meles meles & Norway & $33.3(3 / 9)$ & {$[27]$} \\
\hline P. falciformis & Meles meles & UK & $0.8(1 / 118)$ & [26] \\
\hline P. falciformis & Meles meles & Italy & $52.6(10 / 19)$ & {$[58]$} \\
\hline P. falciformis & Meles meles & Spain & $3.5(3 / 85)$ & [32] \\
\hline P. falciformis & Mustela erminea & UK & $13.5(5 / 37)$ & [59] \\
\hline P. pridhami & Neovison vison & Canada & $8.6(13 / 152)$ & [42] \\
\hline P. pridhami & Neovison vison & Canada & $2.1(1 / 48)$ & {$[30]$} \\
\hline P. pridhami & Mustela erminea & Canada & $12.5(8 / 40)$ & {$[30]$} \\
\hline Perostrongylus sp. & Neovison vison & Spain & $2.0(1 / 50)$ & [33] \\
\hline
\end{tabular}


injection. The dynamics of larval development in snails is not known for P. pridhami. The prepatent period for this species was 23-28 days in experimentally infected minks [21], slightly longer than for P. falciformis in European badgers [11, 62]. As demonstrated for other lungworms of carnivores, $P$. pridhami can be transmitted to minks after ingestion of paratenic hosts (mice, birds, amphibians and fish) [21] but no such information is available for $P$. falciformis.

Additional information is provided on the development of $P$. pridhami in minks experimentally infected via gastric tube with L3 from terrestrial snails [37]. The first moult in minks (L3 to L4) occurred $3 \mathrm{dpi}$ and the final moult (L4 to L5) at $7 \mathrm{dpi}$ [37]. The migration in the minks included penetration of the stomach wall, crossing the peritoneal cavity and the diaphragm, followed by penetration of the visceral pleura of the lungs, all these occurring within the first 24 hours [37]. The migration pattern and last two moults for P. falciformis in European badgers are not known. Anderson [21] also described the morphology of L1-L3 of P. pridhami which seem to be similar to that of the larvae of $P$. falciformis ([11, 62]; present study). L1-L3 of $P$. pridhami are all illustrated in detail [21].

As concluded by Hancox [25], although the European badger is affected by a wide range of parasites, average rates of infection will not have a significant effect on host population regulation. However, individuals may be affected by a high parasite load. Lesions and symptoms produced by $P$. falciformis in European badgers have been described previously $[8,10,27,29,60]$. Additionally, lesions consistent with a possible $P$. falciformis infection in M. erminea were found in the UK $[59,60]$. In North America, lesions produced by $P$. pridhami in minks have also been described [21, 37, 38]. Generally, the pathology caused by the two species of Perostrongylus is similar and results in vomiting (though after experimental infection), coughing (usually when large numbers of parasites are present) and can be complicated by the presence of co-infections [i.e. with Filaroides martis (Werner, 1782) in minks]. However, the clinical signs are known only from experimental infections. The importance of co-infections with Angiostrongylus daskalovi Janchev \& Genov, 1988 in European badgers [63] on the clinical outcome is unknown.

The lesions are produced either by infective larval migration and are located at various levels (stomach, peritoneum, pleura) or by larvae migrating through the lung parenchyma and adults. Generally, adults of P. falciformis are found either in subpleural granulomas or embedded in the lung parenchyma (present study). Similar subpleural nodules were found also in minks infected with $P$. pridhami $[37,38]$. The histological lesions in our study are to date the most detailed and largely similar to the lesions observed in other studies on $P$. falciformis $[27,29,59]$ or P. pridhami [38].

\section{Conclusions}

Molecular phylogenetic and morphological data support the validity of the genus Perostrongylus, with probably two species: P. falciformis in European badgers in Europe and P. pridhami in minks in North America. Moreover, Aelurostrongylus becomes a monotypic genus, with $A$. abstrusus as the type- and only species. Interestingly, the two genera clearly belong to two different evolutionary branches: Perostrongylus is grouped together with the genera Filaroides and Parafilaroides (both in family Filaroididae), whereas Aelurostrongylus belongs to a single branch, with no sister groups. The present study also demonstrated for the first time that $C$. aspersum snails are suitable intermediate hosts. Several aspects remain unknown. One question is which species of Perostrongylus is found in American minks invasive to Europe. The role of paratenic hosts in the life-cycle of $P$. falciformis is also a matter to be explored. Moreover, molecular data from $P$. pridhami will bring further proof for the phylogenetic position of Perostrongylus among metastrongyloids.

\section{Acknowledgements \\ We are indebted to people who contributed to the sample collection (hunters, forestry workers, friends). Further, we acknowledge C. Henrich for her excellent technical assistance in molecular biology. \\ Availability of data and materials \\ The data supporting the conclusions of this article are included within the article. Representative sequences were submitted to the GenBank database under the accession numbers KY365435-KY365437. Voucher specimens are available in the collection of the Museum of Parasitology, Department of Parasitology and Parasitic Diseases, University of Agricultural Sciences and Veterinary Medicine Cluj-Napoca, Romania under accession numbers CJ005077, CJ005086. The dataset and reference materials are available from the corresponding author upon request.}

\section{Authors' contributions}

GD collected samples, performed necropsies and wrote the manuscript. ADM collected samples, wrote the manuscript and coordinated the study. JH: collected samples and performed the phylogenetic analysis. VC performed the experimental life-cycle; FAT carried out the histopathology analysis; MAC performed the larval morphological description and illustrations. FGB collected samples, participated in necropsies and revised the manuscript. CB collected samples, carried out the phylogenetic analysis, provided critical comments on the manuscript. AMI participated in the sample collection and performed the molecular analyses. AA essentially contributed to the sample collection and performed necropsies. DO critically revised the text, coordinated the experimental life-cycle. CMG performed the morphological identification, collected samples and coordinated the study. All authors read and approved the final manuscript.

\section{Ethics approval and consent to participate}

The study was performed in accordance with the national and European rules and regulations for research ethics. No live vertebrates were used in this study.

\section{Consent for publication}

Not applicable.

Competing interests

The authors declare that they have no competing interests. 


\section{Publisher's Note}

Springer Nature remains neutral with regard to jurisdictional claims in published maps and institutional affiliations.

\begin{abstract}
Author details
'Department of Parasitology and Parasitic Diseases, University of Agricultural Sciences and Veterinary Medicine Cluj-Napoca, Cluj-Napoca, Romania. ${ }^{2}$ Institute of Parasitology, Justus Liebig University Giessen, Giesen, Germany. ${ }^{3}$ Dipartimento di Medicina Veterinaria, Università degli Studi di Bari, Str. prov. per Casamassima km 3, 70010 Valenzano, Bari, Italy. ${ }^{4}$ Department of Pathology, University of Agricultural Sciences and Veterinary Medicine Cluj-Napoca, Cluj-Napoca, Romania. ${ }^{5}$ Department of Game and Wildlife Diseases, University of Agricultural Sciences and Veterinary Medicine Cluj-Napoca, Cluj-Napoca, Romania. ${ }^{6}$ Department of Pathology, Faculty of Veterinary Medicine, University of Sarajevo, Zmaja od Bosne 90, 71000 Sarajevo, Bosnia and Herzegovina.
\end{abstract}

Received: 29 June 2018 Accepted: 24 September 2018

Published online: 30 October 2018

\section{References}

1. Carreno RA, Hoberg EP. Evolutionary relationships among the Protostrongylidae (Nematoda: Metastrongyloidea) as inferred from morphological characters, with consideration of parasite-host coevolution. J Parasitol. 1999;85:638-48.

2. Carreno RA, Nadler SA. Phylogenetic analysis of the Metastrongyloidea (Nematoda: Strongylida) inferred from ribosomal RNA gene sequences. J Parasitol. 2003;89:965-73.

3. Cameron TWM. Studies on three new genera and some little-known species of the nematode family Protostrongylidae Leiper, 1926. J Helminthol. 1927:5:1-24.

4. Mueller A. Helminthologisch Mittheilungen. Dtsch Z Sportmed. 1927;17: 58-70.

5. Railliet A. Rectification de la nomenclature d'apres les traveaux recents. Rec Med Vet. 1898;75:171-4.

6. $\quad$ Fry W, Stewart JT Jr. Studies on Aelurostrongylus abstrusus (Railliet 1898) Cameron 1927. J Parasitol. 1931;18:34-9.

7. Kamensky SN. The systematic position of the genera Metastrongylus Wost. and Protostrongylus g. n. among the other Strongylidae. Sbornik Trudov Khar'kovokogo Vet Inst. 1905;7:17-50.

8. Schlegel M. Die lungenwurmseuche beim dachs. Berl Munch Tierarzt Wochenschr. 1933:49:341-4.

9. Böhm LK, Gebauer O. Zum System der Familie Metastrongylidae Leiper, 1908. Zool Anz. 1934;105:287-94.

10. Schlegel M. Die Lungenwurmseuche beim dachs. II. Berl Munch Tierarztl Wochenschr. 1934;50:369-73.

11. Wetzel R. Zur Biologie and systematischen Stellung des Dachslungenwurmes. In: Livro Jubilar do Professor Lauro Travassos. Rio de Janeiro: Instituto Oswaldo Cruz; 1938. p. 531-6.

12. Dougherty EC. The genus Aelurostrongylus Cameron, 1927 (Nematoda: Metastrongylidae), and its relatives; with descriptions of Parafilaroides, gen. nov., and Angiostrongylus gubernaculatus, sp. nov. Proc Helminthol Soc Wash. 1946;13:16-25.

13. Seneviratna P. Studies on the family Filaroididae Schulz, 1951. J Helminthol. 1959;33:123-44

14. Hsü HF. A study of some Strongyloidea and Spiruroidea from French IndoChina and of Thelazia chungkingensis Hsü, 1933 from China. Z Parasitenkd. 1935;7:579-600.

15. Anderson RC. Keys to genera of the superfamily Metastrongyloidea. In: Anderson RC, Chabaud AG, Willmott S, editors. CIH keys to the nematode parasites of vertebrates No. 5. Farnham Royal Bucks, UK: Commonwealth Agricultural Bureau; 1978. p. 1-40.

16. Lesage $C$. Etude de la protostrongylose dans la population de lièvres européens (Lepus europaeus) dans le sud est de la France: approche épidémiologique et écologique. PhD Thesis. Reims: University of Reims Champagne-Ardenne; 2014.

17. Anderson RC, Chabaud AG, Willmott $\mathrm{S}$. Keys to the Nematode Parasites of Vertebrates: Archival volume. Wallingford: CABl; 2009.

18. Gibbons LM. Keys to the Nematode Parasites of Vertebrates. Supplementary volume. Wallingford: CABl; 2010.
19. Anderson RC. Further studies on the taxonomy of metastrongyles (Nematoda: Metastrongyloidea) of Mustelidae in Ontario. Can J Zool. 1963;41:801-9.

20. Asakawa M, Ohbayashi M, Ow-Yang CK. Studies on the parasite fauna of Malaysia I. A redescription of Strongylus brauni Linstow, 1897, and the establishment of a new genus, Viverrostrongylus. Jpn J Vet Res. 1986;34:195-201.

21. Anderson RC. The systematics and transmission of new and previously described metastrongyles (Nematoda: Metastrongylidae) from Mustela vison. Can J Zool. 1962:40:893-920.

22. Anderson RC, Fyvie A. Observations on Aelurostrongylus falciformis (Schlegel) of Mustela vison in Ontario. J Parasitol. 1961;47(Suppl. 1):43.

23. Prestwood AK. Didelphostrongylus hayesi gen. et sp. n. (Metastrongyloidea: Filaroididae) from the opossum, Didelphis marsupialis. J Parasitol. 1976;62:272-5.

24. Stubbe M. Zur biologie der raubtiere eines abgeschlossenen waldgebietes. Sitzungsber Ges Naturf Freunde Berlin. 1965;11:73-102.

25. Hancox M. Parasites and infectious diseases of the Eurasian badger (Meles meles L.): a review. Mammal Rev. 1980;10:151-62.

26. Jones GW, Neal C, Harris EA. The helminth parasites of the badger (Meles meles) in Cornwall. Mammal Rev. 1980;10:163-4.

27. Davidson RK, Handeland K, Gjerde B. The first report of Aelurostrongylus falciformis in Norwegian badgers (Meles meles). Acta Vet Scand. 2006;48:6-10.

28. Demiaszkiewicz AW, Filip KJ, Pyziel AM. The first report of Aelurostrongylus falciformis (Schlegel, 1933) (Nematoda, Metastrongyloidea) in badger (Meles meles) in Poland. Ann Parasitol. 2017:63:117-20.

29. Stevanović O, Trbojević I, Nikolić S, Santrač V. The first reported case of advanced aelurostrongylosis in Eurasian badger (Meles meles, L. 1758) in Bosnia and Herzegovina: histopathological and parasitological findings. Parasitol Res. 2018. https://doi.org/10.1007/s00436-018-5984-6.

30. Jennings DH, Threlfall W, Dodds DG. Metazoan parasites and food of shorttailed weasels and mink in Newfoundland, Canada. Can J Zool. 1982;60:180-3.

31. Kennedy MJ. Synopsis of the Parasites of Vertebrates of Canada - Helminths and Protozoa of Terrestrial Mammals. Edmonton: Department of Agriculture, Animal Health Division; 1986

32. Torres J, Miquel J, Motjé M. Helminth parasites of the Eurasian badger (Meles meles L.) in Spain: a biogeographic approach. Parasitol Res. 2001;87:259-63.

33. Martínez-Rondán FJ, de Ybáñez MR, Tizzani P, López-Beceiro AM, Fidalgo LE, Martínez-Carrasco C. The American mink (Neovison vison) is a competent host for native European parasites. Vet Parasitol. 2017;247:93-9.

34. Dorney RS, Lauerman LH Jr. A helminthological survey of wild mink in Wisconsin. Bull Wildl Dis Assoc. 1969;5:35-6.

35. Kontrimavichus VL. Helminths of Mustelids and Trends in Their Evolution. Moscow, Russia: Nauka; 1969

36. Dailey MD. The transmission of Parafilaroides decorus (Nematoda: Metastrongyloidea) in the California sea lion (Zalophus californianus). Proc Helminthol Soc Wash. 1970;37:215-22.

37. Stockdale PHG. The development, route of migration, and pathogenesis of Perostrongylus pridhami in mink. J Parasitol. 1970;56:559-66.

38. Stockdale PHG. Pulmonary lesions in mink with a mixed infection of Filaroides martis and Perostrongylus pridhami. Can J Zool. 1970;48:757-9.

39. Ko RC, Anderson RC. Tissue migration, growth, and morphogenesis of Filaroides martis (Nematoda: Metastrongyloidea) in mink (Mustela vison). Can J Zool. 1972:50:1637-49.

40. Barber DL, Lockard LL. Some helminths from mink in southwestern Montana, with a checklist of their internal parasites. Great Basin Nat. 1973:33:9.

41. Gibbons LM, Krishnasamy M. Malayometastrongylus diardinematus n. g., n. sp. (Metastrongyloidea: Angiostrongylidae) from Rattus rattus diardii in Malaysia and a redescription of Thaistrongylus harinasutai Ohbayashi, Kamiya \& Bhaibulaya, 1979. Syst Parasitol. 1986;8:107-15.

42. Martin PA, McDaniel TV, Hughes KD, Hunter B. Mercury and other heavy metals in free-ranging mink of the lower Great Lakes basin, Canada, 19982006. Ecotoxicology. 2011;20:1701-12.

43. Varodi El, Malega AM, Kuzmin Yl, Kornyushin W. Helminths of wild predatory mammals of Ukraine nematodes. Vestn Zool. 2017:51:187-202.

44. Willcox HP, Coura JR. A new design of the Baermann, Moraes, Coutinho's technique for the isolation of nematode larva. Mem Inst Oswaldo Cruz. 1989;84:563-5.

45. Colella V, Giannelli A, Brianti E, Ramos RA, Cantacessi C, Dantas-Torres F, Otranto D. Feline lungworms unlock a novel mode of parasite transmission. Sci Rep. 2015;5:13105.

46. Nunn G. Nematode molecular evolution. An investigation of evolutionary patterns among nematodes based upon DNA sequences. PhD Thesis. Nottingham: University of Nottingham; 1992. 
47. Gasser RB, Chilton NB, Hoste H, Beveridge I. Rapid sequencing of rDNA from single worms and eggs of parasitic helminths. Nucleic Acids Res. 1993;21:2525-6.

48. Chilton NB, Huby-Chilton F, Gasser RB, Beveridge I. The evolutionary origins of nematodes within the order Strongylida are related to predilection sites within hosts. Mol Phylogenet Evol. 2006;40:118-28.

49. Porazinska DL, Giblin-Davis RM, Faller L, Farmerie W, Kanzaki N, Morris K, et al. Evaluating high-throughput sequencing as a method for metagenomic analysis of nematode diversity. Mol Ecol Res. 2009;9:1439-50.

50. Bowles J, Blair D, McManus DP. Genetic variants within the genus Echinococcus identified by mitochondrial DNA sequencing. Mol Biochem Parasitol. 1992;54:165-73

51. Folmer O, Black M, Hoeh W, Lutz R, Vrijenhoek R. DNA primers for amplification of mitochondrial cytochrome $c$ oxidase subunit I from diverse metazoan invertebrates. Mol Mar Biol Biotechnol. 1994;3:294-9.

52. Muñoz P, Hirzmann J, Rodriguez E, Moroni M, Taubert A, Gibbons L, Hermosilla C, Gómez M. Redescription and first molecular characterization of the little known feline neurotropic nematode Gurltia paralysans (Nematoda: Metastrongyloidea). Vet Parasitol Reg Stud Rep. 2017;10:119-25.

53. Katoh K, Standley DM. MAFFT multiple sequence alignment software version 7: improvements in performance and usability. Mol Biol Evol. 2013; 30:772-80

54. Dereeper A, Guignon V, Blanc G, Audic S, Buffet S, Chevenet F, et al. Phylogeny.fr: robust phylogenetic analysis for the non-specialist. Nucleic Acids Res. 2008;36:465-9.

55. Gerichter CB. Studies on the nematodes parasitic in the lungs of Felidae in Palestine. Parasitology. 1949:39:251-62.

56. Kadenatsii, AN. Helminthofauna of mammals of Crimea and experience of recovery of domestic animals from basic helminthiases. Helminthol. Laboratory of Acad. Sciences of the USSR. Chair of parasitology of Omsk Vet. in-ta. 1957; p. 137.

57. Kontrimavichus VL, Delyamure SL, Boev SN. Metastrongyloids of domestic and wild animals. Fundamentals of Nematology 1976;26:1-237. (Translated by Oxonian Press Pvt. Ltd., New Delhi, India, 1985).

58. Magi M, Banchi C, Barchetti A, Guberti V. The parasites of the badger (Meles meles) in the north of Mugello (Florence, Italy). Parassitologia. 1999:41:533-6.

59. McDonald RA, Day MJ, Birtles RJ. Histological evidence of disease in wild stoats (Mustela erminea) in England. Vet Rec. 2001;149:671-5.

60. Simpson VR, Tomlinson AJ, Stevenson K, McLuckie JA, Benavides J, Dagleish MP. A post-mortem study of respiratory disease in small mustelids in southwest England. BMC Vet Res. 2016;12:72.

61. Rudolph R. Ceroidbildung und deren ätiologie in dachslungen. Berl Munch Tierarztl Wochenschr. 1968:81:13-5.

62. Wetzel R. Zur entwicklung des dachslungenwurmes Filaroides falciformis (Schlegel, 1933). Sitzungsber Ges Naturf Freunde Berlin. 1937;1:1-3.

63. Gherman CM, Deak G, Matei IA, Ionică AM, D'Amico G, Taulescu M, et al. A rare cardiopulmonary parasite of the European badger, Meles meles: first description of the larvae, ultrastructure, pathological changes and molecular identification of Angiostrongylus daskalovi Janchev \& Genov, 1988. Parasit Vectors. 2016;9:423.

Ready to submit your research? Choose BMC and benefit from:

- fast, convenient online submission

- thorough peer review by experienced researchers in your field

- rapid publication on acceptance

- support for research data, including large and complex data types

- gold Open Access which fosters wider collaboration and increased citations

- maximum visibility for your research: over $100 \mathrm{M}$ website views per year

At $\mathrm{BMC}$, research is always in progress.

Learn more biomedcentral.com/submissions 